\title{
Utilization of non-pneumatic anti-shock garment and associated factors for postpartum hemorrhage management among health care professionals' in public hospitals of Jimma zone, south-West Ethiopia, 2019
}

\author{
Gadisa Bekele*, Gemechu Terefe, Makeda Sinaga and Sena Belina
}

\begin{abstract}
Background: Non- pneumatic anti-shock garment is a unique, life -saving first-aid device made of neoprene and velcro, which is used for treatment of women with postpartum hemorrhage. Maternal mortality in the world still very high and postpartum hemorrhage is the leading cause of maternal mortality worldwide.

Objective: This study was aimed to assess the utilization of non-pneumatic anti-shock garment and associated factors for postpartum hemorrhage management.

Methods: Facility based cross-sectional studies design both quantitative and qualitative data collection methods were employed among 210 health care professionals and 10 key informants respectively. Bivariable and multivariable logistic regression was done to identify factors associated with non-pneumatic anti-shock garment utilization. Qualitative data was transcribed, translated and triangulated with quantitative findings.

Results: Seventy six (36.2\%) of the respondents used non-pneumatic anti-shock garment in their hospitals for management of post-partum hemorrhage. Having good knowledge [(AOR $=3.96,95 \% \mathrm{Cl}:(1.67,9.407)]$, having positive attitude $[(A O R=3.54,95 \% \mathrm{Cl}:(1.37,9.13)]$, attending training $[A O R=13.156,95 \% \mathrm{Cl}:(4.81,36.00]$, having two and above non-pneumatic anti-shock garment at their hospitals $[A O R=8.7,95 \% \mathrm{Cl}:(2.89,26.20)]$ were significantly associated with utilization of non-pneumatic anti-shock garment. ... "I didn't use non-pneumatic anti-shock garment for the management of postpartum hemorrhage complication before because I have no training and experience how to use it." Conclusion: The utilization of non-pneumatic anti-shock garment for the management of postpartum hemorrhage was low. Having positive attitude, having good knowledge and training on non-pneumatic anti-shock garment were statically associated with its use. The health care professionals that involved in the maternity service should be trained on how to use this important garment in the management of postpartum hemorrhage.
\end{abstract}

Keywords: Postpartum hemorrhage, Anti-shock garment, Maternal mortality

\footnotetext{
* Correspondence: gaaddisaab@gmail.com

School of Nursing and Midwifery, Faculty of health Sciences, Institute of

health, Jimma University, P.O.BOX:378 Jimma, Ethiopia
}

C C The Author(s). 2020 Open Access This article is licensed under a Creative Commons Attribution 4.0 International License, which permits use, sharing, adaptation, distribution and reproduction in any medium or format, as long as you give appropriate credit to the original author(s) and the source, provide a link to the Creative Commons licence, and indicate if changes were made. The images or other third party material in this article are included in the article's Creative Commons licence, unless indicated otherwise in a credit line to the material. If material is not included in the article's Creative Commons licence and your intended use is not permitted by statutory regulation or exceeds the permitted use, you will need to obtain permission directly from the copyright holder. To view a copy of this licence, visit http://creativecommons.org/licenses/by/4.0/. The Creative Commons Public Domain Dedication waiver (http://creativecommons.org/publicdomain/zero/1.0/) applies to the data made available in this article, unless otherwise stated in a credit line to the data. 


\section{Plain English summary}

The leading cause of maternal mortality (deaths from pregnancy and childbirth related complications) is obstetric hemorrhage in which a woman bleeds heavily, most often immediately after giving birth. A woman somewhere in the world dies every 4 min from this kind of complication.

The Non-pneumatic Anti-shock Garment is a first-aid device used to stabilize women who are suffering from obstetric hemorrhage and shock. It is a simple device helps women survive delays in getting to a hospital and getting the treatment that they need. It can be applied by anyone after a short, simple training.

Respondents were asked on utilization of Nonpneumatic Anti-shock Garment for Postpartum Hemorrhage Management. Knowledge and attitude of care providers was assessed quantitatively and additional information was collected from key informants qualitatively to explore factors in detail.

Of 210 Seventy six (36.2\%) used NASG for postpartum hemorrhage management while $63.8 \%$ never applied it for postpartum hemorrhage complication management. The reasons stated by respondents those did not use non-pneumatic anti-shock garment, (35.4\%) were due to lack of experience and (23.8\%) due to lack of awareness about availability of the instruments.

Periodic training for health professionals on the use of non-pneumonic anti-shock garment for management of obstetric hemorrhage is important.

\section{Introduction}

Non- pneumatic Anti-Shock Garment (NASG) is a unique, life -saving first -aid device made of neoprene and velcro, which is used for women with obstetric hemorrhage. It can be applied by anyone, even those without medical training. Non-pneumatic anti-shock garment has a unique role in hemorrhage and shock management because it is meant to be used with, other technologies. Currently, it is the only tool first aids in stabilizing pulse and blood pressure after a woman has gone into shock from obstetric hemorrhage. Nonpneumatic anti-shock garment can reverse shock and can be used at the same time with other hemorrhage and shock treatments, such as: uterine massage, uterotonics, blood transfusions, vaginal procedures and surgery, uterine balloon tamponed [1, 2]. Non-pneumatic anti-shock garment was developed in 1970s by the United States (US) National Aeronautics and Space Administration (NASA)/ Ames [3].

International Confederation of Midwives (ICM) and the International Federation of Gynecology and Obstetrics (FIGO) recommended the non-pneumatic antishock garments as it reduce mortality [4].
The non-pneumatic anti-shock garments like bottom half suit and consists of three pairs the first of segments, the first segments are placed around the patient's legs and the second three segments are placed around her pelvis and abdomen during the application for postpartum hemorrhage. A ball in segment 5 is placed over the woman's umbilicus (belly button, navel), adding more pressure. Non-pneumatic anti-shock garment is to be worn until the patient's vital sign have stabilized for $2 \mathrm{~h}$ or more, include blood loss $<50 \mathrm{ml} / \mathrm{hr}$, pulse $<100 \mathrm{bpm}$ and systolic blood pressure $>100 \mathrm{mmhg}$. Removing of NASG begins from lowest segments and proceeds upward by allowing $15 \mathrm{~min}$ between removals each segment for redistribution of blood. But if her hemodynamic status has not become unstable use the "Rule of 20", that means her pulse has not increased by more than $20 \mathrm{bpm}$ and her systolic blood pressure has not decreased by more than $20 \mathrm{mmHg}$. If pulse and blood pressure remain stable, open the next segment pair $[5,6]$.

Non-pneumatic anti-shock garment introduced in Ethiopia by Clinton Health Access Initiative (CHAI) as a pilot project to prevent postpartum hemorrhage in Oromia and Tigray regions [7].

Using non-pneumatic anti-shock garment can reduce the time to recovery from shock, decrease blood loss to external, increases both external and internal abdominal pressure [8].

"Maternal mortality is the death of a woman during pregnant or within 42 days of termination of pregnancy, irrespective of the duration and site of the pregnancy, from any cause related to or provoked by the pregnancy but not from accidental or incidental causes" [9]. The death of a woman in childbirth or from pregnancyrelated events is a devastating experience for the woman's family, her partner and her surviving children and is also devastating for all involved in her care [10].

The maternal mortality ratio in developing countries in 2015 is 239 per 100,000 live births versus 12 per 100, 000 live births in developed countries [11]. Maternal mortality rate in Africa is the highest, and it is estimated at 500 deaths per 100, 000 live births. Fifty six percent (56\%) occur in sub-Saharan Africa a region that accounts for only $21 \%$ of the world population [12]. In Ethiopia, maternal mortality still high. According to the World Bank report of 2018 the Ethiopian maternal mortality was 353 per 100, 0000 live birth [13].

Postpartum hemorrhage is one of the leading causes of maternal mortality and morbidity, accounted for approximately $27 \%$ of global maternal deaths, is defined as vaginal bleeding more than $500 \mathrm{ml}$ after vaginal delivery, blood loss of more than $1000 \mathrm{ml}$ after cesarean delivery and more than $1500 \mathrm{ml}$ after cesarean hysterectomy [14]. 
In 2014 globally over $661,000(27.1 \%)$ maternal death was occurred due obstetric hemorrhage. More than two thirds of reported hemorrhage deaths were classified as postpartum hemorrhage. About 19.7\% was occurred in developing countries. Eastern Asia accounted about 26.1\% and in Sub-Saharan Africa around 200,000 maternal deaths was caused by postpartum hemorrhage [15].

According to the study conducted in Jimma University specialized hospital on the trend of maternal death from 2010 to 2014 most of maternal deaths occurred because of direct obstetric causes. Hemorrhage was the leading cause of death accounted about $54 \%$ in every year of the study, and it is the cause for more than half this death was occurred due to postpartum hemorrhage especially between 4 and 7 days of postpartum [16].

In addition to its direct cause of maternal of death, postpartum hemorrhage has also short and long term impacts like chronic illness, disability, increasing of death, poor growth and development of their children, hepatic dysfunction [17].

A woman suffering from hypovelimic shock secondary to postpartum hemorrhage can die within $2 \mathrm{~h}$ except she receives immediate blood transfusion and appropriate emergency obstetric care [18].

Non-pneumatic anti-shock garment is one of the first management tools for hypovolemic shock secondary to obstetric hemorrhage that is helpful in resuscitating and sustaining women in severe obstetric hemorrhagic shock. There was neither mortality nor clinically significant morbidity in this reappraisal so with out of this advice maternal mortality and morbidity very high [19].

The study conducted on the non-pneumatic antishock garment at Global Health study showed that with help of the non-pneumatic anti-shock garment for postpartum hemorrhage management blood loss decreased by $42-55 \%$, vital signs and restoration of circulatory stabilized rapidly, maternal mortality was reduced by $66 \%$, morbidity decreased by $44-66 \%$ and there were $32-73 \%$ lower extreme adverse outcomes (EAOs) [20]. At referral, tertiary-level facilities using non-pneumatic antishock garment for the management of postpartum hemorrhage reduce maternal mortality by $48 \%$ [21].

Study done in Ibadan Nigeria in 2014 utilization of non-pneumatic anti-shock garment for the management of post-partum hemorrhage was low, which was only $14.5 \%$ [22].

Low utilization of non-pneumatic anti-shock garment in Bayelsa State in which $46.4 \%$ of Midwives used for the management of postpartum hemorrhage this indicated low utilization of non-pneumatic anti-shock garment among respondents despite the efficacy of nonpneumatic anti-shock garment in reducing maternal morbidity and mortality related postpartum hemorrhage-related complication [23].
However, regardless of effective and many benefits associated with the use of Non-Pneumatic Anti shock garment in the management of postpartum hemorrhage its utilization is still very low. Even in Ethiopia still there is no any study showed utilization of non-pneumatic antishock garment for the management of postpartum hemorrhage by health care professionals. This study was therefore designed to assess health care professional utilization of non-pneumatic anti-shock garment and associated factors for the management of postpartum hemorrhage in Public hospitals of Jimma Zone South West Ethiopia.

\section{Methods and material}

\section{Study area and the study period}

The study was conducted in Jimma zone public hospitals, Oromia regional state south-West Ethiopia. Jimma zone far $350 \mathrm{Km}$ from Addis Abbaba. The Jimma zone has a total area of 119,316 Square kilo meters. It has 21 woreda and 1 town administration with a total of 555 kebeles of which 515 of them are rural and 30 are urban. The population projection of 2014/15 of the zone is 3,090,112 with total reproductive age groups of 616,380.

In this zone there were seven public hospitals: Jimma medical center, Shanan Gibe hospital, Agaro Hospital, Limmu Hospital, Seka Hospital, Omo Nada Hospital and Satama Hospital. The study was conducted from April 01 to, 202,019.

\section{Study design}

Facility based cross-sectional study design both quantitative and qualitative methods were employed.

\section{Source and study population}

All health care professionals' who were working in Jimma Zone public Hospitals were source of population. And all health care professionals who were working in Jimma Zone public Hospitals and fulfilled the selection criteria.

\section{Selection criterion Sampling procedure}

The study included a total of 210 included by census sampling technique in quantitative study. An in-depth interview was conducted on 10 key informants in qualitative. These health care professionals were chosen purposively based on their involvement in the use of NASG and Head of maternity ward. Participants who participated in in-depth interview were not involved in quantitative study. 


\section{Operational definitions and definitions of terms}

Utilization of non-pneumatic anti-shock garment (NAG) is measured based on the response to the question whether health care professionals used NASG for the management of postpartum hemorrhage at least one time [22, 24].

Knowledge scale The respondents score of total knowledge questions those who below $50 \%$ were graded as having poor knowledge while those $50.0 \%$ and above were graded as having good knowledge [25].

Attitude scale: The attitude was considered "Positive" if the percentage score was $50 \%$ and above more and "Negative" if less than $50 \%$.

\section{Measurements and data collection procedure}

Aself-administered semi- structured questionnaire was used to collect data from study participants. The instrument was adapted and developed from different literatures [22-24, 26, 27]. It was prepered in English version and the questionnaire contains four parts which include socio demographic status eight questions, knowledge of Non-pneumatic anti-shock garment eight questions, attitude of health care professional regarding Non- pneumatic anti-shock garment eight questions and the responses consist five likert scales which were strongly agree, agree,neutral, disagree and strongly disagree and the fourth part was organizational (hospitals) related questions. The attitude statetment five likert scale for analysis was become three likert scale. Strongly agree and agree became agree and disagree and strongly disagree became disagree and neutral. Before the actual data collection, the questionnaire was pre-tested on $10 \%$ of health care professionals in Metu Karl Hospitals and appropriate corrections were made such as logical order of some questions, some words difficult to understand were revised. The overall standardized cronbach's alpha for internal consistent or the reliability score of measurement was 0.86 .

In-depth interview was carried out by the principal investigator and note taker on who agreed to be interviewed.

\section{Data analysis}

Following the data collection, data were coded, and entered to a computer using Epidata version 3.1 and then exported to SPSS version 23.0 for analysis. Descriptive statistics and binary logistic regressions analysis were performed. In the binary logistic regression, both binary and multivariable analyses were carried out. All the variables were entered into bivariate analysis and those independent variables with a $\mathrm{p}$ - value $<0.25$ in crude analysis was considered as a candidate for multivariable analysis and those variables with a $p$ value $<0.05$ in multivariable analysis were considered as statically significant of non-pneumatic anti-shock garment utilization. Multi-collinearity was checked to see the linear correlation among the independent variables by using the variance inflation factor and standard error. None of the variables yield inflation factor $>10$ and standard error $>2 \quad(\mathrm{VIF}<4.66$ and Std. $\mathrm{E}<.137)$ and they were not dropped from multivariable analyses. Hosmer and Lemeshow's test was found to be insignificant ( $p$-value $=0.158)$ and Omnibus test was significant $(p$-value $=0.000)$ which indicate that the model was fitted. Finally, the result of the analysis was presented in texts, tables and graphs as appropriate. For qualitative study, first for each individual tape recorded was transcribed and after reading again and again then data was translated. Then data were coded by number for each translated after data were coded similar numbers pooled together and the theme was developed. Finally presented in narratives \& used to support the quantitative findings.

\section{Ethical considerations}

Before data collection, ethical clearance was obtained from the institutional review board of Jimma University, Institute of health and submitted to each hospital. Permission was obtained from each hospital prior to data collection. The written consent was obtained from each participant that participation was voluntary and they have the right to withdraw at any time from the study. The informed consent was comprised the study purpose and procedures, potential risks and benefits, voluntary participation and right of withdrawal, the information provided by each respondent was kept strictly confidential.

\section{Results}

\section{Socio demographic characteristics}

A total of 220 questionnaires were distributed to the participants but only 210 were replied; the rest 10 did not fill the questionnaire correctly and excluded from the analysis with response rate of $95.5 \%$.

The mean age of the respondents was 28.36 years. Half of participants 106 (50.5\%) were in the age group of 25-29. Among the respondents, 121 (57.6\%) were male. Nearly $(51.9 \%)$ of respondents were married. Majority of them were Oromo by ethnicity (70.0\%). Eighty six (41.0\%) were Muslim by religion. Professionally 145 (69.0\%) were Midwives. One hundred forty eight (70.5\%) had $1-5$ years of work experiences (Table 1$)$.

\section{Respondents' knowledge of non-pneumatic anti-shock garment}

This study indicated that, majority $(80.0 \%)$ of respondents had heard about non-pneumatic anti-shock 
Table 1 Socio-demographic characteristics of health care professional who were working in Jimma zone public Hospitals Southwest Ethiopia, April 2019

\begin{tabular}{|c|c|c|}
\hline Variables & Frequency & Percentage \\
\hline \multicolumn{3}{|l|}{ Age in years } \\
\hline $20-24$ & 39 & 18.6 \\
\hline $25-29$ & 106 & 50.5 \\
\hline $30-34$ & 41 & 19.5 \\
\hline $35-39$ & 24 & 11.4 \\
\hline \multicolumn{3}{|l|}{ Sex } \\
\hline Male & 121 & 57.6 \\
\hline Female & 89 & 42.4 \\
\hline \multicolumn{3}{|l|}{ Marital status } \\
\hline Married & 109 & 51.9 \\
\hline Single & 101 & 48.1 \\
\hline \multicolumn{3}{|l|}{ Ethnicity } \\
\hline Oromo & 147 & 70.0 \\
\hline Amhara & 33 & 15.7 \\
\hline Tigrai & 14 & 6.7 \\
\hline Gurage & 9 & 4.23 \\
\hline Others & 7 & 3.33 \\
\hline \multicolumn{3}{|l|}{ Religion status } \\
\hline Muslim & 86 & 41.0 \\
\hline Orthodox & 77 & 36.7 \\
\hline Protestant & 41 & 19.5 \\
\hline Others & 6 & 2.9 \\
\hline \multicolumn{3}{|l|}{ Profession } \\
\hline Midwives & 145 & 69.0 \\
\hline Nurses & 46 & 21.9 \\
\hline Medical doctor & 5 & 2.4 \\
\hline Emergency surgery & 14 & 6.7 \\
\hline \multicolumn{3}{|l|}{ Educational level } \\
\hline Diploma & 50 & 23.7 \\
\hline Bachelor degree & 142 & 67.6 \\
\hline Masters & 14 & 6.7 \\
\hline Specialist & 4 & 1.9 \\
\hline \multicolumn{3}{|l|}{ Years of experience } \\
\hline $1-5$ years & 148 & 70.5 \\
\hline $6-10$ years & 55 & 26.2 \\
\hline 11 years and above & 7 & 3.3 \\
\hline
\end{tabular}

Other: Ethnicity: Wolayita, Hadiya, Silte, Kafa Religion: Wakefata, Catholic

garment while 42 (20.0\%) never heard before. Ninety one of the respondents heard from hospital (54.2. \%). Ninety eight $(58.3 \%)$ of the respondents said that nonpneumatic anti-shock looks like trousers and 55 (32.7\%) said bottom half of suit. Ninety seven $(57.7 \%)$ of the respondents correctly mentioned that non-pneumatic anti-shock garment has six parts. Regarding the function of Non-pneumatic anti-shock garment, 21.0\% mentioned that non-pneumatic anti-shock garment increases blood flow to vital organs. Concerning the criteria for the application of non-pneumatic anti-shock garment for women with postpartum hemorrhage about 98 (36.8\%) said NASG applied when blood loss was greater than $750 \mathrm{ml}$, (Table 2).

About 59.5\% respondents' had good knowledge towards non-pneumatic anti-shock garment.

\section{Attitudes of health care professionals towards utilization of non-pneumatic anti shock garment}

Regarding to the attitudes of the respondents towards utilization of NASG for the management of postpartum hemorrhage, about one hundred forty seven $(70 \%)$ of the respondents agreed that NASG is necessary for the management of postpartum hemorrhage in all settings and $5.7 \%$ disagree. One hundred forty two (67.6\%) respondents agreed that NASG can used along with standard treatment protocols of postpartum hemorrhage management and $9(4.3 \%)$ disagreed. Concerning the time required to apply NASG (Table 3).

Regarding the attitudes of respondents towards nonpneumatic anti-shock garment utilization more than half of (53.58\%) had positive attitudes.

\section{Distribution of health care professionals by their organization (hospitals)}

Regarding the organizational factors, 87 (41.4\%\%) respondents were working at general hospitals, $126(60 \%)$ of the respondents said that their hospitals have two and above number of non-pneumatic anti-shock garment. About 59 (28.1\%) respondents have training on nonpneumatic anti-shock garment utilization (Table 4).

\section{Utilization of non-pneumatic anti-shock garment}

Concerning the utilization of non-pneumatic anti-shock garment by health professionals, seventy six (36.2\%) used NASG for postpartum hemorrhage management while 63.8\% never applied it for postpartum hemorrhage complication management. The reasons stated by respondents those did not use non-pneumatic anti-shock garment, (35.4\%) were due to lack of experience and (23.8\%) due to lack of awareness about availability of the instruments (Table 5).

Factors associated with utilization of non-pneumatic antishock garment

The bivariate analysis result revealed that types of professions, educational status, knowledge of respondents, attitude of respondents, training on NASG, types of 
Table 2 Knowledge of NASG among health care professionals who were working in Jimma zone public Hospitals Southwest Ethiopia, April 2019

\begin{tabular}{|c|c|c|}
\hline Variables & Frequency & Percentage \\
\hline \multicolumn{3}{|l|}{$\begin{array}{l}\text { Known NASG as it used for pph } \\
\text { complication mgt }\end{array}$} \\
\hline Yes & 168 & 80.0 \\
\hline No & 42 & 20.0 \\
\hline \multicolumn{3}{|l|}{ Source of information (first) } \\
\hline Training & 36 & 21.4 \\
\hline Conference & 6 & 3.6 \\
\hline Hospital & 91 & 54.2 \\
\hline From textbook & 26 & 15.5 \\
\hline Electronics & 4 & 2.4 \\
\hline Other & 5 & 3.0 \\
\hline \multicolumn{3}{|l|}{ NASG look like } \\
\hline Gown & 15 & 8.9 \\
\hline Trousers & 98 & 58.3 \\
\hline Bottom half of suit & 55 & 32.7 \\
\hline \multicolumn{3}{|l|}{ How many parts have the NASG } \\
\hline Four & 39 & 23.2 \\
\hline Six & 97 & 57.7 \\
\hline Eight & 24 & 14.3 \\
\hline Nine & 8 & 4.8 \\
\hline \multicolumn{3}{|l|}{ What is the function NASG? ${ }^{*}$} \\
\hline Prevent Shock & 97 & 16.7 \\
\hline Stabilize the women in shock & 104 & 17.9 \\
\hline Reverse shock & 54 & 9.3 \\
\hline Decrease blood loss & 98 & 16.8 \\
\hline Compress blood vessels & 91 & 15.6 \\
\hline Increase blood flow to vital organs & 122 & 21.0 \\
\hline No response & 8 & 1.4 \\
\hline Other & 7 & 1.2 \\
\hline \multicolumn{3}{|l|}{ Know proper use of NASG } \\
\hline Yes & 122 & 72.6 \\
\hline No & 46 & 27.4 \\
\hline Total & 168 & 100.0 \\
\hline \multicolumn{3}{|l|}{$\begin{array}{l}\text { Non-pneumatic anti-shock garment } \\
\text { applied for women with PPH when* }\end{array}$} \\
\hline Bleeding > $750 \mathrm{ml}$ & 98 & 36.8 \\
\hline systolic blood pressure $<90 \mathrm{~mm}$ & 84 & 31.6 \\
\hline Pulse $>110 \mathrm{bpm}$ & 84 & 31.6 \\
\hline \multicolumn{3}{|l|}{ NASG removed when } \\
\hline Blood loss $<50 \mathrm{ml} / \mathrm{hr}$., & 71 & 21.8 \\
\hline Pulse $<100$ bpm & 88 & 27.1 \\
\hline Systolic blood pressure $>100 \mathrm{mmhg}$ & 90 & 27.7 \\
\hline Normal shock index & 76 & 23.4 \\
\hline Good Knowledge & 100 & 59.5 \\
\hline Poor knowledge & 68 & 40.5 \\
\hline
\end{tabular}

${ }^{*}$ Multiple responses are possible hospitals, number of NASG and place where placed after use were significantly associated utilization of NASG.

All the significant independent variables in a bivariate analysis were entered together in a multivariable logistic regression using backward method to determine final predictors of utilization of non-pneumatic anti-shock garment controlling for potential confounders. Accordingly; knowledge level, attitude, having training on NASG, number of NASGs hospitals have were independent predictors of utilization of non-pneumatic antishock garments. In this study health care professionals who had a good knowledge about NASG were 3.957 times more likely to use the NASG as compared to health professionals who had poor knowledge about NASG[AOR $=3.957,95 \%$ CI: $(1.67,9.407, p=0.002)]$.

This finding was supported by qualitative finding.

A health care provider working at labor ward explained NASG as; I have used NASG for the management of postpartum hemorrhage many times. NASG is not a drug but it is cloth used for postpartum hemorrhage management. It stabilizes woman in shock, increase blood flow to vital organ and decrease blood loss. It is not simple removed after applied. To remove it there is a rule called rule of 20 after measuring the vital sign blood pressure and pulse in normal range at least for 2 hours then each segment should be removed every 15 min starting from segment one to six. If the vital sign changes by 20 in between removing means pulse increased by $20 \mathrm{bpm}$ and BP decreased by $20 \mathrm{mmhg}$, the NASG should be reapplied.

Regarding the attitudes of health care professionals those who had positive attitude toward the NASG utilization were 3.54 times more likely to use NASG than those who had negative attitude towards NASG utilization for postpartum hemorrhage management [(AOR $=3.54,95 \%$ CI:(1. 37, 9.13, $p=0.009)]$.

.... Staff working at labor said that "I have the knowledge of the non-pneumatic anti-shock garment as it used for postpartum hemorrhage to reverse shock and stabilize the women condition but I didn't use it because I preferred other methods like normal saline, warm cloth and blood transfusion for woman with postpartum haemrrahge."

Concerned with status of training by health care professionals on NASG use, those health professionals who received training on the use of NASG were 13.156 times more likely use NASG as compared with who didn't received training on NASG use (AOR: 13.156, 95\% CI: $(4.89,36.00, p=0.0001)]$. This is supported by qualitative finding. For instance:

... A 25 years old health professional said that "I didn't use NASG for the management of postpartum hemorrhage complication before because I have no training and experience how to use it. If I receive 
Table 3 Attitudes towards NASG utilization among health care professionals who were working in Jimma zone public Hospitals Southwest Ethiopia, April 2019

\begin{tabular}{|c|c|c|c|}
\hline \multirow[t]{2}{*}{ Variables } & Agree & neutral & Disagree \\
\hline & No (\%) & No (\%) & No $(\%)$ \\
\hline $\begin{array}{l}\text { The use of non-pneumatic anti shock garment is necessary for the management of postpartum } \\
\text { hemorrhage in all settings. }\end{array}$ & $147(70)$ & $49(23.3)$ & $14(6.7)$ \\
\hline NASG used along with standard treatment protocols of postpartum hemorrhage. & $143(68.1)$ & $55(26.2)$ & $12(5.7)$ \\
\hline NASG can be applied with minimum procedures in short period of time. & $100(47.6)$ & $55(26.2)$ & $55(26.2)$ \\
\hline Removal NASG requires a lot of procedures that takes time. & $120(57.1)$ & $40(19.1)$ & $50(23.8)$ \\
\hline Anti-shock garment is only beneficial to people in the rural areas/primary care settings & $28(13.3)$ & $55(26.2)$ & $127(60.5)$ \\
\hline Manual removal of placenta is possible with NASG in place & $141(67.1)$ & $43(20.5)$ & $26(12.4)$ \\
\hline Anti-shock garment is effective in patients with cervical lacerations & $104(49.5)$ & $67(31.9)$ & 39 (18.6) \\
\hline The garment should be a must in every health care facility that has maternity service & $144(68.6)$ & $35(16.7)$ & $31(14.8)$ \\
\hline
\end{tabular}

training I use it without any difficult because I have seen the health professionals who were trained can apply and remove easily."

Relating to NASG, those health care professional whose hospitals had two and above NASGs, were 8.7 times more likely to use NASGs as compared with those health professionals' hospital had only one NASG for postpartum hemorrhage management of complication (AOR: 8.70, 95\% CI: $(2.89,26.20, p=0.0001)]$ (Table 6).

This finding was supported by qualitative finding. For instance:

.... A 32 year head of maternity ward said that, previous we have three non-pneumatic anti-shock garments that our staffs applied for the mothers who have postpartum hemorrhage. But now there is only one NASG at our hospital and the others were referred mother to

Table 4 Distribution of health care professionals by their organizations who were working in Jimma zone public Hospitals Southwest Ethiopia, April 2019

\begin{tabular}{lll}
\hline Variables & Frequency & Percentage \\
\hline What is the level of your hospital? & 58 & 27.6 \\
Primary hospital & 87 & 41.4 \\
General hospital & 65 & 31 \\
Tertiary hospital & & \\
Received training on NASG & 59 & 28.1 \\
Yes & 151 & 71.9 \\
No & & \\
How many numbers NASG & & \\
available at your hospital? & 84 & 40 \\
One & 126 & 60 \\
Two and above & & 59 \\
Where does NASG placed after & & 41 \\
use in your hospital? & 124 & \\
In labor ward & 86 & \\
In not labor ward &
\end{tabular}

referral hospital by NASG that they never gave back for us and left there. Currently we rarely used NAG because when NASG we have applied for the mother and other presented with similar case we never applied it because we have only one and also before the NASG is cleaned we never use it that mother presented without NASG.

\section{Discussion}

Non-pneumatic anti-shock garment (NASG) can prevent the postpartum hemorrhage complication by decreasing blood flow to the lower extremities and increasing blood flow to vital organs like brain, heart, and lung.

Based on this finding $36.2 \%$ of the respondents utilized the non-pneumatic anti-shock garment on the client for the management of postpartum hemorrhage. This finding was almost similar finding in Ibadan Nigeria and Sokoto State Specialist Hospital (35\%) in both study areas $[24,26]$. How every it was higher when compared with study done in Ondo state Nigeria that $14.1 \%$ of respondents' utilized non-pneumatic anti-shock garment for postpartum hemorrhage management [22]. The difference may be due sample size difference, sampling technique used. On the contrary it was lower compared to finding in Bayelsa State Nigeria and Benin Central Hospital that 46.4 and $42 \%$ of the respondents used non-pneumatic anti-shock garment for postpartum hemorrhage management respectively [23, 25]. The slight difference in utilization might be due to difference between study participants in which only Midwives participated in case of study conducted in both study areas and also may be due to variation in sampling technique used.

This study also revealed that knowledge, attitude, nonpneumatic anti-shock garment number, training status of the respondents and their utilization of NASG had significant association with $P$-value $<0.05$.

Good utilization of non-pneumatic anti-shock garment was seen among health care professionals who had good 
Table 5 Utilization of non- pneumatic anti-shock garment among health care professionals who were working in public Hospitals of Jimma Zone South West Ethiopia, April 2019

\begin{tabular}{|c|c|c|}
\hline Variables & Frequency & Percentage \\
\hline \multicolumn{3}{|l|}{ Used NASG for the management of PPH? } \\
\hline Yes & 59 & 36.2 \\
\hline No & 134 & 63.8 \\
\hline \multicolumn{3}{|l|}{ Do you use NASG every time there is PPH? } \\
\hline Yes & 32 & 15.24 \\
\hline No & 43 & 20.48 \\
\hline Never use & 134 & 63.81 \\
\hline \multicolumn{3}{|l|}{ If no, when do you use it?* } \\
\hline Severe PPH & 41 & 38.3 \\
\hline Shock & 43 & 40.2 \\
\hline When other method is fail & 23 & 21.5 \\
\hline \multicolumn{3}{|l|}{ Do you use it, when the need arise in your hospital? } \\
\hline Yes & 62 & 29.52 \\
\hline No & 14 & 6.67 \\
\hline Never use & 134 & 63.81 \\
\hline \multicolumn{3}{|l|}{ If no, why? * } \\
\hline It is difficult to assemble & 10 & 41.7 \\
\hline It is not ready available for using & 9 & 37.5 \\
\hline I do not know much about it & 5 & 20.8 \\
\hline \multicolumn{3}{|l|}{ Reason for non-utilization* } \\
\hline Availability of other method & 30 & 14.3 \\
\hline Effective management of third stage of labor & 28 & 21.4 \\
\hline Lack of experience & 58 & 27.6 \\
\hline Not aware existence of NASG in the hospital & 39 & 18.6 \\
\hline The garment is not convenient & 9 & 4.3 \\
\hline
\end{tabular}

*Multiple responses are possible knowledge about NASG. Those who have good knowledge utilize non-pneumatic anti-shock garment about four times more likely as compared to having poor knowledge. This implies that good knowledge exerts a positive effect on the extent of health care professionals' utilization of NASG. This is supported by the study conducted in Ondo State and Benin Central Hospital, that there was association between respondents' knowledge and their utilization of non-pneumatic anti-shock garment $[25,27]$. This may be due to the fact that good knowledge improves the confidence and readiness of the health care professionals' to utilize NASG for postpartum hemorrhage management and increase their ability to use it appropriately. However it was differ from Bayelsa State Nigeria that there was no significant association between respondents' knowledge and their utilization of non-pneumatic anti-shock garment [23]. The discrepancy may be due the difference of sample size, this study included different types of health care professionals.

Another independent factor showed that there was more utilization of NASG for postpartum haemorrhage management among health care professionals who had positive attitude. This implies that a positive attitude regarding NASG exerts a positive effect on the extent of health care professionals' NASG utilization practice. Health care professionals' have positive attitude there is a big tendency to utilize properly. It is different from the study finding in Bayelsa State Nigeria that there is no association between respondents' attitude and nonpneumatic anti-shock garment utilization [27]. This difference may be due to difference in variable categorization, variation in setting from place to place, may be due sampling technique used for sample selection (SRS) and may also due variation in the population participated in the study.

Table 6 Multivariable logistic regression showing independent factors of utilization of non-pneumatic anti-shock garment among health care professionals working in Jimma zone public Hospitals South West Ethiopia, April, 2019

\begin{tabular}{|c|c|c|c|c|c|c|}
\hline \multirow[t]{2}{*}{ Variables } & \multirow[t]{2}{*}{ Categories } & \multicolumn{2}{|c|}{ Utilized NASG } & \multirow[t]{2}{*}{ COR $(95 \% \mathrm{Cl})$} & \multirow[t]{2}{*}{ AOR $(95 \% C l)$} & \multirow[t]{2}{*}{$p$-value } \\
\hline & & $\begin{array}{l}\text { Yes } \\
\text { N (\%) }\end{array}$ & $\begin{array}{l}\text { No } \\
\text { N (\%) }\end{array}$ & & & \\
\hline \multirow[t]{2}{*}{ General Knowledge } & Good knowledge & $61(36.31 \%)$ & $39(23.21 \%)$ & \multirow{2}{*}{$\begin{array}{l}5.53(2.74,11.13) \\
1.0\end{array}$} & \multirow{2}{*}{$\begin{array}{l}3.967(1.67,9.407) \\
1.0\end{array}$} & \multirow[t]{2}{*}{0.002} \\
\hline & Poor knowledge & 15 (8.93\%) & 53 (31.55\%) & & & \\
\hline \multirow[t]{2}{*}{ Total Attitude } & positive attitude & 66 (31.4\%) & $47(22.4 \%)$ & $12.212(5.75,25.96)$ & \multirow[t]{2}{*}{$\begin{array}{l}3.540(1.37,9.13) \\
1.0\end{array}$} & \multirow[t]{2}{*}{0.009} \\
\hline & Negative attitude & $10(4.8 \%)$ & $87(41.4 \%)$ & 1.0 & & \\
\hline \multirow[t]{2}{*}{ Training status } & Yes & 47 (22.4\%) & $12(5.7 \%)$ & $16.477(7.77,34.96)$ & $13.156(4.81,36.00)$ & \multirow[t]{2}{*}{0.0001} \\
\hline & No & 29 (19.21\%) & $122(80.79 \%)$ & 1.0 & 1.0 & \\
\hline \multirow[t]{2}{*}{ NASG number } & One & $13(6.2 \%)$ & $71(33.8 \%)$ & 1.0 & 1.0 & \multirow[t]{2}{*}{0.0001} \\
\hline & Two and above & $63(30 \%)$ & $63(30 \%)$ & $5.461(2.75,10.85)$ & $8.70(2.89,26.20)$ & \\
\hline
\end{tabular}


This study showed that good utilization of nonpneumatic anti-shock garment was seen among health care professionals who took training on non-pneumatic anti-shock garment as compared to those who have no training. Those health professionals who trained on nonpneumatic anti-shock were about thirteen times more likely used than those who had no training. This may be due to the fact that attending training can help health care professionals to get more knowledge on how to apply, remove non-pneumatic anti-shock garment and this can improve their utilization of non-pneumatic antishock garment.

In this study non-pneumatic anti-shock garment number was other factor that statically associated with utilization of non-pneumatic anti shock garment by health care professionals. Hospitals having two and above non-pneumatic anti-shock garment were around nine times more likely used than those who have one.

Health care professionals play a vital role in the reduction of maternal mortality and morbidity in all health facilities. Postpartum hemorrhage is one of the leading causes of maternal mortality especially in the developing countries. It is therefore, important that health care providers are always abreast with current techniques and equipment used in preventing and management of postpartum hemorrhage. This study showed low utilization of non-pneumatic anti shock garment among the health care providers, and this important concept included in maternal health program and policy planners.

\section{Strength and limitations}

The study involved both quantitative and qualitative methods of data collections to maximize the reliability of the data collected. The questionnaire was prone to social desirability bias; hence it assesses self-reported regarding utilization of NASG, there might be over-reporting of a behavior. Recall bias was there because the majority of the health care professionals were asked about their past utilization of NASG. In addition to these, the lack study in Ethiopia and adequate studies did out of Ethiopia on this topic make comparison and discussion difficult.

\section{Conclusion and recommendation}

This study showed that of the respondents' utilized nonpneumatic anti shock garment for the management of post-partum hemorrhage low. The study also identified factors associated utilization of non-pneumatic antishock garment. The independent factors associated with utilization of non-pneumatic anti-shock garment were having good knowledge of health professional; attend training on non-pneumatic anti-shock garment, positive attitudes towards non-pneumatic anti-shock garment utilization and more number of non-pneumatic antishock garments available. Periodic training for health professionals on the use of non-pneumonic anti-shock garment for management of obstetric hemorrhage is useful.

\section{Abbreviations \\ ATSM: Active third stage management; EAO: Extreme adverse outcome; FIGO: Federation of Gynecology and Obstetrics; ICM: International Confederation of Midwives; NASG: Non-pneumatic Anti-shock Garment; $\mathrm{PPH}$ : Postpartum hemorrhage}

\section{Acknowledgements}

We would like to thank Jimma Public Hospitals of Jimma zone for all the help and support given for us during the data collection period. We also thank Jimma University institute of health for permitting us to conduct this study.

\section{Ethics approval and consent to particpate}

All procedures performed in studies involving human participants were in accordance with the ethical standards of the institutional and/or national research committee and with the declaration and its later amendments or comparable ethical standards. Before the commencement of the study, ethical approval was secured from the Jimma Ethical Review Board. Written informed consent was obtained from all individual participants included in the study.

\section{Authors' contributions}

Gemechu Terefe, Gadisa Bekele, Mekida Sinaga and Sena Balina conceived and designed the protocol. Gemechu Terefe, contributed on data analysis, and checked the draft. Gadisa Bekele and Gemechu Terefe prepared

manuscript. All authors read and approved the final paper.

\section{Funding}

Jimma University covered only the survey cost for this study and there is no any funding organization.

\section{Availability of data and materials}

The spreadsheet data supporting the findings of this work is available at the hands of the corresponding authors.

\section{Consent for publication}

The purpose of the study was explained to the study participants at the time of data collection and verbal consent was secured from each participant before the start of data collection. Confidentiality was ensured by not including names or other identifiers in the data collection tool. The right of the participants to refuse participation or not to answer any of the questions was respected.

\section{Competing interests}

All authors declared that they have no conflict of interests.

Received: 5 September 2019 Accepted: 4 March 2020

Published online: 17 March 2020

\section{References}

1. Snow J. The Non-Pneumatic Anti-Shock Garment (NASG): Saving Mothers' Lives Through Innovation in Timor-Leste. 2015.

2. Miller S, Bergel EF, El Ayadi AK, et al. Non-pneumatic anti-shock garment (NASG), a first-aid device to decrease maternal mortality from obstetric hemorrhage: a cluster randomized trial. PLoS One. 2013;8(10):764-677.

3. Hensleigh PA. Anti-shock garment provides resuscitation and haemostatic for obstetric hemorrhage. BJOG. 2002;109:1377-84.

4. Miller S, Martin HB, Morris JL. Anti-shock garment in postpartum hemorrhage. Best Pract Res Clin Obstet Gynecol. 2008;22(6):1057-74.

5. Miller S. Introduction to the Non-Pneumatic Anti-Shock Garment (NASG) for obstetric haemorrhage. UCSF Safe Motherhood Program; 2013. http://www. Safemotherhood.ucsf.edu.

6. World Health Organization. WHO recommendations for the prevention and treatment of postpartum haemorrhage. Geneva: World Health Organization; 2012. Available from: http://www.who.int/reproductivehealth/publications/ maternal_perinatal_health/9789241548502/en/. 
7. ICM/FIGO. International Confederation of Midwives and International Federation of Gynecologists' and Obstetricians Joint Statement: Management of the Third Stage of labor to Prevent Post-partum Hemorrhage 2003.

8. Demeke, Z. Non-pneumatic anti-shock garment pilot in Ethiopia to reduce maternal mortality secondary to obstetric hemorrhage. CHAl Ethiopia. Presented at the Global Maternal Health Conference, 2013.

9. WHO Health statistics and information system maternal mortality ratio definitions. Retrieved 2017: Available from: http://www.who.int/healthinfo/ statistics/indmaternal mortality/en/.

10. World Health Organization, UNICEF, United Nations Population Fund (UNFPA). Managing complications in pregnancy and childbirth: a guide for midwives and doctors. 2nd ed. Geneva: World Health Organization; 2017.

11. World Health Organization Maternal mortality https://www.who.int > News > Fact sheets > Detail 2018.

12. Global, regional, and national levels and trends in maternal mortality between 1990 and 2015, with scenario-based projections to 2030: a systematic analysis by the UN Maternal Mortality Estimation Inter-Agency Group. Lancet. 2016;387(10017):462-74.

13. Maternal death or maternal mortalities defined by world health organization (WHO) as "the ... All data is from the world Bank. ... . Retrieved 2018-06-27. Available from: https:/www.google.com/search?q= List+of+countries+by+maternal+mortality+rate.

14. DC Dutta's Textbook of Obstetrics: Kolkata India, eighth edition 2015. Available from: https://www.academia.edu/36303073/Textbook_of_DC_ Duttas_OBSTETRICS_8ed

15. Lale $S$ et al. Global causes of maternal death: a WHO systematic www. thelancet.com/lancetgh $2014 \mathrm{Vol} 2$.

16. Legesse et al Trend of maternal deaths from 2010 to 2014 in JUSH International Journal of Women's Health 2017:9.

17. Abete T, Kebede B Misganaw, E, Rogers N, Retrospective study of birth outcome and prevalence postpartum morbidity among women who attendend for care in Gonder, North West Ethiopia,2014; 3(125).

18. WHO Managing Complications in Pregnancy and Childbirth: A guide for midwives and doctors. Integrated Management of Pregnancy and Childbirth (IMPAC) Geneva: WHO, Department of Reproductive Health and Research 22, 2000

19. Effectiveness of Non-Pneumatic Anti-Shock Garment (NASG) in Preventing Shock-related Morbidity and Mortality in Severe Hemorrhagic Shock. Crit Care Obst Gyne. 2017;3:3.

20. Laine J. The non-pneumatic anti-shock garment, a first aid device in obstetrical emergencies; 2017.

21. Pileggi-Castro C, Nogueira-Pileggi V , Tunçalp Ö, Oladapo OT, Vogel JP, Souza JP. Non-pneumatic anti-shock garment for improving maternal survival following severe postpartum haemorrhage: a systematic review. Reprod Health. 2015;12(1):28.

22. Ohaeri BM. Assessment of utilization of non-pneumatic anti shock garment (NASG) in the control of post-partum hemorrhage among midwives in selected hospitals in Ondo-state, Nigeria. Int J Caring Sci. 2017;10(1):327.

23. Onasoga OA, Duke E, Danide IU, Jack-Ide IO. Midwives' knowledge and utilization of non pneumatic anti shock garment in reducing complication of postpartum hemorrhage is selected health care facilties in Bayelsa state Nigeria. IntJ Reproductive contraceptive Obstet Gynecol. 2015:977-81.

24. Kolade OA, Tijjani WA, Oladeji MA, Ajibade LA. Midwives' knowledge and utilization of anti shock garment in prevention of postpartum hemorrhage shock at the university college hospital, Ibadan Nigeria. J Nurs Health Sci. 2014;3:9-16

25. Enuku Ca, Adeyemo Fo. Knowledge and use of anti-shock garment among midwives in central hospital, Benin City, Edo state. Lautech journal of Nursing. 2018:23.

26. Kombo SA, Shehu SB, Faroog MA, Yunusa A. Knowledge and utilization of anti-shock garment in prevention of postpartum hemorrhagic shock in specialist hospital Sokoto, Sokoto State Nigeria. DUJOPAS. 2018;4(2):236-44.

27. OGBEYE GB, OHAERI BM, OLATUBI MI. Midwives knowledge and attitude towards the use of anti-shock garment in the control of post partum hemorrhage in selected hospitals in Ondo state. Int J Health Sci Res. 2015; 5(9):389-95

\section{Publisher's Note}

Springer Nature remains neutral with regard to jurisdictional claims in published maps and institutional affiliations.

\section{Ready to submit your research? Choose BMC and benefit from}

- fast, convenient online submission

- thorough peer review by experienced researchers in your field

- rapid publication on acceptance

- support for research data, including large and complex data types

- gold Open Access which fosters wider collaboration and increased citations

- maximum visibility for your research: over $100 \mathrm{M}$ website views per year

At BMC, research is always in progress.

Learn more biomedcentral.com/submissions 